\title{
Vivência dos pais nas etapas hospitalares do método canguru: revisão integrativa
}

\author{
Parent experience in the hospital stages of the kangaroo method: an integrative review \\ Experiencia de los padres en las etapas del hospital del método canguro: una revisión \\ integradora
}

Deusa Daniel de Oliveira Menezes ${ }^{1 *}$, Deisy Vital dos Santos ${ }^{1}$, Aisiane Cedraz Morais².

\begin{abstract}
RESUMO
Objetivo: Descrever a vivência dos pais com o Método Canguru (MC), na primeira e segunda etapa, a partir das publicações científicas brasileiras. Métodos: Revisão integrativa da literatura, realizada nas bases de dados da Literatura Latino-Americana e do Caribe em Ciências da Saúde (LILACS), da Scientific Electronic Library Online (SCIELO) e no Portal de periódicos CAPES/MEC, utilizando o descritor: "Método Canguru", com recorte temporal do ano de 2003 a 2018. Resultados: O MC apresenta benefícios para a díade criança e família, quando promove sentimentos positivos, empoderamento, criação de vínculo e favorece o aleitamento materno. Todavia, também é possível identificar alguns dilemas e dificuldades, como o sentimento de medo e culpa, mudanças na dinâmica familiar e social e temores provenientes do ambiente hospitalar. Isto demanda um processo de construção e desconstrução na relação estabelecida entre a família, a criança e a equipe de saúde, de modo que haja sucesso na utilização do método. Considerações finais $A$ vivência dos pais nas etapas hospitalares do método canguru é permeada por múltiplos sentimentos, vinculados ao método propriamente dito e associados a relação com a equipe de saúde. Identificou-se lacunas quanto a investigação dos aspectos sociais dos pais que vivenciam o MC no SUS.
\end{abstract}

Palavras-chave: Método canguru, Enfermagem neonatal, Família.

\begin{abstract}
Objective: To describe the parents' experience with the Kangaroo Method (MC), in the first and second stages, based on Brazilian scientific publications. Methods Integrative literature review, carried out in the databases of Latin American and Caribbean Literature in Health Sciences (LILACS), Scientific Electronic Library Online (SCIELO) and in the CAPES / MEC journals portal, using the descriptor: "Method Kangaroo ", with a time frame from 2003 to 2018. Results: The MC presents benefits for the child and family dyad, when it promotes positive feelings, empowerment, bonding and favors breastfeeding. However, it is also possible to identify some dilemmas and difficulties, such as the feeling of fear and guilt, changes in family and social dynamics and fears arising from the hospital environment. This demands a process of construction and deconstruction in the relationship established between the family, the child and the health team, so that there is success in using the method. Final considerations: The experience of parents in the hospital stages of the kangaroo method is permeated by multiple feelings, linked to the method itself and associated with the relationship with the health team. Gaps were identified regarding the investigation of the social aspects of parents who experience MC in SUS.
\end{abstract}

Keywords: Kangaroo method, Neonatal nursing, Family.

\footnotetext{
${ }^{1}$ Universidade Federal do Recôncavo da Bahia. Santo Antônio de Jesus - BA.

*E-mail: deusadaniel@gmail.com

2Universidade Estadual de Feira de Santana. Feira de Santana - BA.
}

SUBMETIDO EM: 4/2020

ACEITO EM: 5/2020

PUBLICADO EM: 7/2020

REAS/EJCH | Vol.Sup.n.55 | e3731 | DOI: https://doi.org/10.25248/reas.e3731.2020 Página 1 de 11 


\section{RESUMEN}

Objetivo: Describir la experiencia de los padres con el Método Canguro (MC), en la primera y segunda etapa, basada en publicaciones científicas brasileñas. Métodos: Revisión bibliográfica integral, realizada en las bases de datos de Literatura Latinoamericana y del Caribe en Ciencias de la Salud (LILACS), Biblioteca Electrónica Científica en línea (SCIELO) y en el portal de revistas CAPES / MEC, utilizando el descriptor: "Método Canguro ", con un período de tiempo de 2003 a 2018. Resultados: El MC presenta beneficios para la díada infantil y familiar, cuando promueve sentimientos positivos, empoderamiento, unión y favorece la lactancia materna. Sin embargo, también es posible identificar algunos dilemas y dificultades, como el sentimiento de miedo y culpa, los cambios en la dinámica familiar y social y los temores derivados del entorno hospitalario. Esto exige un proceso de construcción y deconstrucción en la relación establecida entre la familia, el niño y el equipo de salud, para que haya éxito en el uso del método. Consideraciones finales: La experiencia de los padres en las etapas hospitalarias del método canguro está impregnada de múltiples sentimientos, vinculados al método en sí y asociados con la relación con el equipo de salud. Se identificaron lagunas con respecto a la investigación de los aspectos sociales de los padres que experimentan CM en el SUS.

Palabras clave: Método canguro, Enfermería neonatal, Familia.

\section{INTRODUÇÃO}

A taxa de mortalidade infantil, a qual consiste no número de óbitos no primeiro ano de vida, no Brasil concentra-se, sobretudo no primeiro mês (FRANCA EB, et al., 2017). No ano de 2015 a taxa foi de 13,8 mortes por mil nascidos vivos. Salienta-se que essa foi a menor taxa em 11 anos, no entanto, as regiões mais ricas do país, Sul e Sudeste, mostraram taxas de mortalidade infantil abaixo da média nacional, 9,7 e 10,7 respectivamente. Enquanto as regiões Norte, Nordeste e Centro-Oeste apresentaram as seguintes taxas: 18,1, 17,5 e 14, 8 (PNAD, 2015).

Os principais fatores de risco para a mortalidade neonatal são a prematuridade e o baixo peso ao nascer, que juntos representam de $60 \%$ a $70 \%$ da mortalidade infantil no Brasil (MENEZES MAS, et al., 2014). Sabese que há avanços na organização de políticas de saúde brasileiras, contudo a mortalidade infantil, especialmente no componente neonatal, persiste em níveis elevados e os valores divergem entre as regiões do país, demonstrando diferenças de acesso à saúde entre os estados (BRASIL, 2018).

Diante deste cenário, a Política Nacional de Atenção Integral à Saúde da Criança (PNAISC) visa orientar e qualificar as ações e os serviços de saúde da criança no território nacional e é estruturada em sete eixos estratégicos. No eixo I "Atenção humanizada e qualificada à gestação, ao parto, ao nascimento e ao recémnascido" é preconizado a melhoria do acesso, cobertura, qualidade e humanização da atenção obstétrica e neonatal e dentre as ações estratégicas para a efetivação do eixo encontra-se a atenção humanizada ao recém-nascido de baixo peso, com a utilização do Método Canguru (MC) (BRASIL, 2018). O MC consiste em uma tecnologia de assistência neonatal voltado para a melhoria da qualidade do cuidado, desenvolvido em três etapas, estabelecido conforme Portaria SAS/MS n.693 de 05 julho de 2000, e atualizada pela Portaria no 1.683, em 12 de julho de 2007 (BRASIL, 2007).

A primeira etapa tem início no pré-natal de alto-risco e acompanha a internação do recém-nascido (RN) na Unidade de Terapia Intensiva Neonatal (UTIN). Na segunda, o RN é transferido para a Unidade de Cuidados Intermediário Neonatal Canguru (UCINca) e a família é encorajada a assumir a posição canguru pelo maior tempo possível. A terceira etapa inicia na alta hospitalar e caracteriza-se pelo acompanhamento ambulatorial ou domiciliar (GONTIJO TL, et al., 2012).

O período de nascimento do bebê prematuro para as mães é permeado de múltiplos sentimentos como angústia, fragilidades, insegurança, medos e desafios. E diante deste contexto, os pais precisam reelaborar esse nascimento antecipado para dar conta das necessidades reais do seu filho, que inclui a hospitalização, bem como esses sentimentos negativos que surgem concomitantemente (VERONEZ M, et al., 2017). 
A hospitalização do bebê prematuro insere a família no ambiente da UTIN e, segundo Nascimento ACST, et al. (2019), emerge a necessidade de reforçar as estratégias e redes de apoio aos pais no contexto neonatal; bem como desenvolver um novo olhar para as famílias; para que estas saibam e estejam aptas a lidar com os RN submetidos no MC, de maneira que o vínculo seja fortalecido e mantido e que suas dúvidas e inseguranças, em relação ao método, sejam levadas em consideração (BRASIL, 2014).

Assim, frente a importância das tecnologias do cuidado oferecidos ao RN prematuro e/ou de baixo peso, e observando que a formação do vínculo entre a tríade família/criança/profissionais de saúde são essenciais para a boa evolução do quadro clínico do RN, este estudo tem como objetivo descrever a vivência dos pais com o método canguru, na primeira e segunda etapa, a partir das publicações científicas brasileiras.

\section{MÉTODOS}

As buscas foram conduzidas diante da seguinte questão norteadora: Como os pais vivenciam o método canguru, na primeira e segunda etapa? Utilizou-se para o levantamento bibliográfico o Portal de periódicos da Coordenação de Aperfeiçoamento de Pessoal de Nível Superior (CAPES) vinculada ao Ministério da Educação (MEC) (CAPES/MEC), a Bases de Dados da Literatura Latino-Americana em Ciências da Saúde (LILACS), e a Biblioteca Virtual Scientific Electronic Library Online (SciELO).

Como critérios de inclusão foram utilizados apenas artigos originais, publicados no idioma português e que foram realizados no território brasileiro, devido à singularidade das nossas características sociais, econômicas e culturais. Como recorte temporal utilizou-se o período entre 2003 a 2018, levando-se em consideração que no ano 2000 foi implantada a política do MC no Brasil. Exclui-se as teses e dissertações, artigos de revisão, duplicados e editoriais.

A coleta de dados foi realizada no período de maio a agosto de 2018, sendo utilizado apenas o descritor "Método Canguru", uma vez que a tentativa de estratégia de busca com mais de um descritor reduziu sensivelmente o número de artigos elegíveis.

Foram selecionadas 259 publicações na base de dados CAPES/MEC, 151 LILACS e 76 na SCIELO. No primeiro momento compôs a amostra dessa revisão 486 artigos, passando-se a leitura de seus títulos e resumos. Finalizada essa etapa, 23 artigos foram selecionados para serem lidos na íntegra, objetivando ratificar as escolhas através dos critérios de inclusão adotados.

Para categorização dos trabalhos, foi elaborado um instrumento de análise que contempla as seguintes informações: título, autores, ano de publicação, local de coleta dos dados, participantes do estudo, titulação dos autores, banco de dados, objetivo do estudo, metodologia, resultados e considerações. Ao término da leitura crítica dos artigos na íntegra, 8 artigos foram excluídos por não atenderem ao objetivo desta revisão. Sendo assim, 15 artigos compuseram a amostra final desta pesquisa. Este processo está exposto na Figura 1, seguindo a recomendação Prisma (TRICCO AC, et al., 2018). 
Figura 1 - Fluxo do processo de seleção dos estudos para a revisão integrativa da literatura.
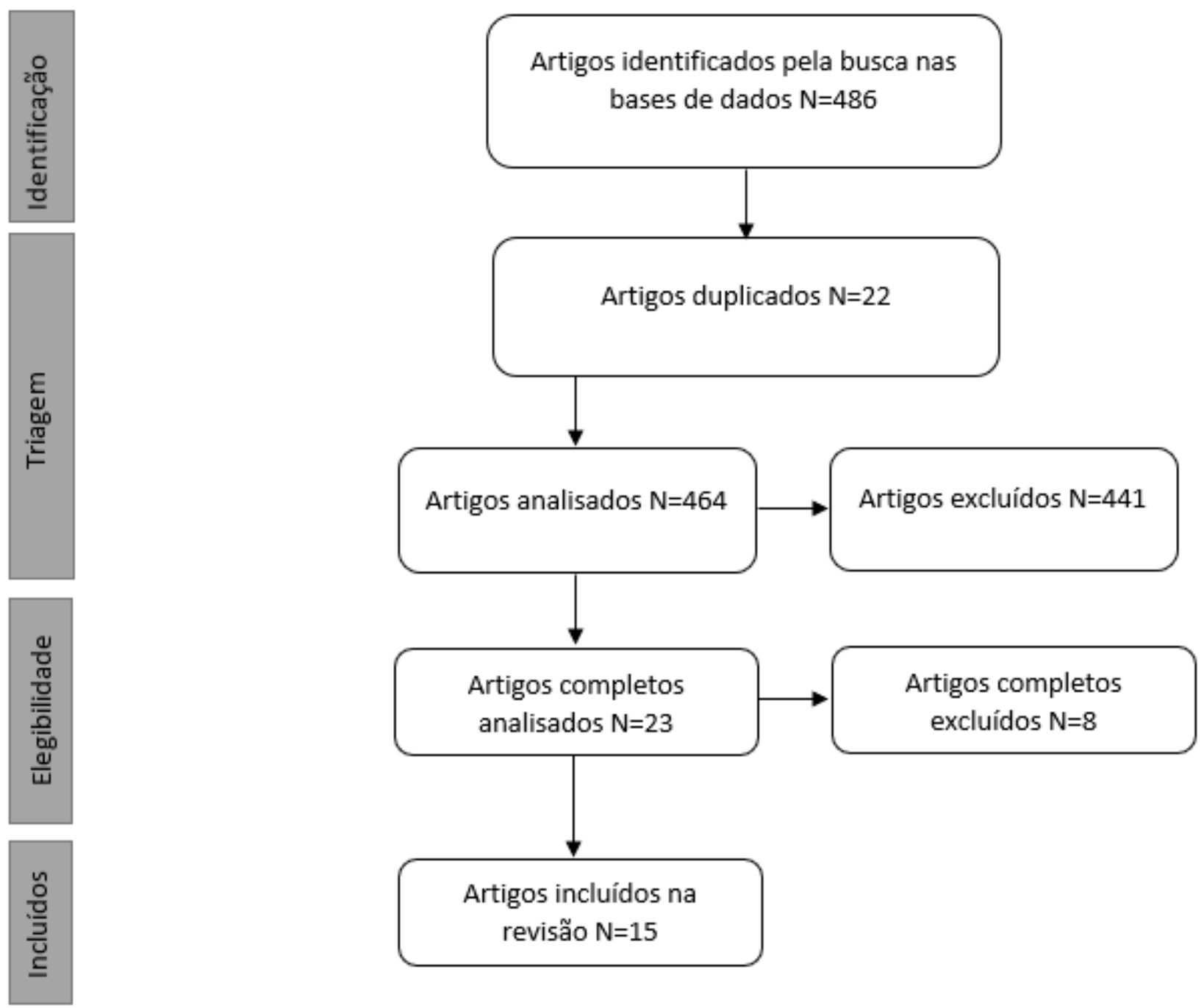

Fonte: Menezes DDO, et al., 2020.

Os artigos selecionados foram sistematicamente categorizados e organizados. Os resultados obtidos foram analisados de forma dissertativo-argumentativa, buscando organizar as tendências convergindo-as ou divergindo-as conforme o conteúdo dos artigos.

A presente revisão integrativa assegura os aspectos éticos, respeitando a autoria dos artigos pesquisados, utilizando para citações e referências dos autores as normas da Associação Brasileira de Normas Técnicas (ABNT).

\section{RESULTADOS}

Os artigos selecionados foram encontrados na base de dados da CAPES e da LILACS, 14 e 1 respectivamente. Quanto a localização geográfica das pesquisas, observou-se que a maior produção ocorreu na região sudeste com 8 dos 15 estudos, seguida da região nordeste com 4 e região sul com 3.

Sobre o ano de publicação foi possível observar que não houve um seguimento gradativo ou linear. $O$ maior número de produção deu-se nos anos de 2010 (3 artigos) e nos anos de 2008 e 2015 (2 artigos cada). Os dados de caracterização dos 15 artigos selecionados para realização desta revisão integrativa estão apresentados no Quadro 1. 
Revista Eletrônica Acervo Saúde / Electronic Journal Collection Health | ISSN 2178-2091

Quadro 1 - Distribuição dos artigos segundo título, base de dados de origem do periódico, local, ano de publicação e nível de evidência. Santo Antônio de Jesus-BA, Brasil, 2018.

\begin{tabular}{|c|c|c|c|c|c|c|}
\hline Autores & Título & Base de dados & Periódico & Local & Ano & Nível de evidência \\
\hline NUNES NP, et al., 2015 & $\begin{array}{c}\text { Método canguru: percepção } \\
\text { materna acerca da vivência na } \\
\text { unidade de terapia intensiva } \\
\text { neonatal }\end{array}$ & CAPES MEC & Rev Bras Promoção Saúde & Ceará & 2015 & Nível 4 \\
\hline $\begin{array}{c}\text { SPEHAR MC e SEIDL } \\
\text { EM, } 2013\end{array}$ & $\begin{array}{c}\text { Percepção materna sobre o } \\
\text { contato pele a pele com o } \\
\text { prematuro através da posição } \\
\text { canguru }\end{array}$ & CAPES MEC & $\begin{array}{l}\text { Rev pesq. cuid. fundam. } \\
\text { Online }\end{array}$ & Bahia & 2013 & Nível 4 \\
\hline $\begin{array}{l}\text { VIANA MRP, et al., } \\
2018\end{array}$ & $\begin{array}{l}\text { Vivência de mães de prematuros } \\
\text { no método mãe canguru }\end{array}$ & CAPES MEC & Rev Fund Care Online. & Piauí & 2018 & Nível 4 \\
\hline $\begin{array}{l}\text { CAETANO LC, et al., } \\
2005\end{array}$ & $\begin{array}{l}\text { Vivendo no método canguru a } \\
\text { tríade mãe-filho-família }\end{array}$ & CAPES MEC & $\begin{array}{l}\text { Rev Latino-am } \\
\text { Enfermagem }\end{array}$ & Minas Gerais & 2005 & Nível 4 \\
\hline $\begin{array}{l}\text { ARIVABENE JC e } \\
\text { TYRRELL MAR, } 2010\end{array}$ & $\begin{array}{l}\text { Método mãe canguru: vivências } \\
\text { maternas e contribuições para a } \\
\text { enfermagem }\end{array}$ & CAPES MEC & $\begin{array}{l}\text { Rev. Latino-Am. } \\
\text { Enfermagem }\end{array}$ & Espírito Santo & 2010 & Nível 4 \\
\hline $\begin{array}{l}\text { OLIVEIRA MC, et al., } \\
2015\end{array}$ & $\begin{array}{c}\text { Método canguru: percepções das } \\
\text { mães que vivenciam a segunda } \\
\text { etapa }\end{array}$ & CAPES MEC & J. res.: fundam. care. Online & Sul do Brasil & 2015 & Nível 4 \\
\hline $\begin{array}{l}\text { FURLAN CEFB, et al., } \\
2003\end{array}$ & $\begin{array}{l}\text { Percepção dos pais sobre sobre } \\
\text { a vivência no método mãe- } \\
\text { canguru }\end{array}$ & CAPES MEC & Rev Latino-am Enfermagem & São Paulo & 2003 & Nível 4 \\
\hline $\begin{array}{l}\text { LARA KL e KIND L, } \\
2014\end{array}$ & $\begin{array}{l}\text { Processos de subjetivação } \\
\text { vivenciados por mães em uma } \\
\text { unidade de neonatologia }\end{array}$ & CAPES MEC & Psicologia em Estudo & Minas Gerais & 2014 & Nível 4 \\
\hline
\end{tabular}

REAS/EJCH | Vol.Sup.n.55 | e3731 | DOI: https://doi.org/10.25248/reas.e3731.2020 Página $\mathbf{5}$ de 11 
Revista Eletrônica Acervo Saúde / Electronic Journal Collection Health | ISSN 2178-2091

\begin{tabular}{|c|c|c|c|c|c|c|}
\hline $\begin{array}{l}\text { GUIMARAES GP e } \\
\text { MONTICELLI M, } 2007\end{array}$ & $\begin{array}{l}\text { A formação do apego pais/recém- } \\
\text { nascido pré-termo e/ou de baixo } \\
\text { peso no método mãe-canguru: } \\
\text { uma contribuição da enfermagem }\end{array}$ & CAPES MEC & $\begin{array}{l}\text { Texto \& Contexto } \\
\text { Enfermagem }\end{array}$ & Santa Catarina & 2007 & Nível 4 \\
\hline $\begin{array}{l}\text { MOREIRA JO, et } \\
\quad \text { al.,2009 }\end{array}$ & $\begin{array}{c}\text { Programa mãe-canguru e a } \\
\text { relação mãe-bebê: pesquisa } \\
\text { qualitativa na rede pública de } \\
\text { betim }\end{array}$ & CAPES MEC & Psicologia em Estudo & Minas Gerais & 2009 & Nível 4 \\
\hline $\begin{array}{l}\text { MOURAI GN, et al., } \\
2015\end{array}$ & $\begin{array}{l}\text { A vivência do método canguru: a } \\
\text { percepção do pai }\end{array}$ & CAPES MEC & Rev enferm UFPE online & Rio de Janeiro & 2015 & Nível 4 \\
\hline NEVES PN, et al., 2010 & $\begin{array}{c}\text { Atenção humanizada ao recém- } \\
\text { nascido de baixo-peso (método } \\
\text { mãe canguru): percepções de } \\
\text { puérperas }\end{array}$ & CAPES MEC & Rev Gaúcha Enferm & Paraná & 2010 & Nível 4 \\
\hline $\begin{array}{l}\text { CAMPOS ACS, et al., } \\
2008\end{array}$ & $\begin{array}{l}\text { Vivência no método mãe } \\
\text { canguru: percepção da mãe }\end{array}$ & CAPES MEC & Rev. Rene & Ceará & 2008 & Nível 4 \\
\hline $\begin{array}{l}\text { MARTINS AJVS e } \\
\text { SANTOS IMM, } 2008\end{array}$ & $\begin{array}{l}\text { Vivendo do outro lado do método } \\
\text { canguru: a experiência materna }\end{array}$ & CAPES MEC & Ver.Eletr.Enf. & Rio de Janeiro & 2008 & Nível 4 \\
\hline $\begin{array}{c}\text { DUARTE ED e SENA } \\
\text { RR, } 2004\end{array}$ & $\begin{array}{c}\text { Experiências de mulheres no } \\
\text { desenvolvimento do método } \\
\text { canguru }\end{array}$ & LILACS & Rev. Min. Enf & Minas Gerais & 2004 & Nível 4 \\
\hline
\end{tabular}

Fonte: Menezes DDO, et al., 2020.

REAS/EJCH | Vol.Sup.n.55 | e3731 | DOI: https://doi.org/10.25248/reas.e3731.2020 Página 6 de 11 
No que se refere a categoria profissional dos autores dos artigos, 13 artigos foram produzidos por enfermeiras, restando 2 de autoria de psicólogas. Pode-se inferir que a predominância da produção por enfermeiras deve-se pelas ações de cuidado serem específicas da profissão, onde o contato direto e contínuo com os pacientes é mais frequente (JESUS NC, et al., 2015).

Quanto ao campo de coleta de dados identificou-se que todos os artigos ocorreram em hospitais públicos brasileiros, confirmando que a inciativa e efetivação do $\mathrm{MC}$, como política pública no Brasil, se dá por intermédio do Sistema Único de Saúde (SUS) (BRASIL, 2018).

Após organizar os dados com os principais resultados dos estudos foi possível descrever parcialmente 0 perfil dos participantes das pesquisas, visto que apenas 6 artigos trataram deste quesito e neles, as participantes eram apenas as puérperas. Assim, a caracterização social dessas mães foram: baixo nível de escolaridade, baixa renda familiar, solteiras e multíparas.

Quanto à abordagem metodológica utilizada nos artigos, percebeu-se a prevalência das pesquisas descritivas, portanto os artigos com nível 4 de evidência. Esse tipo de estudo tem como objetivo a descrição das características de determinado fenômeno, no caso a vivência dos pais no MC. Para a análise do nível de evidência dos artigos da revisão utilizou-se a classificação proposta por Stetler CB, et al. (1998).

\section{DISCUSSÃO}

Os principais achados foram reunidos em três categorias temáticas: Vivendo o ideal: benefícios do MC para a díade bebê-família; Vivendo o real: dilemas e dificuldades na efetivação do MC; Des(construção) da tríade no MC: família-bebê-equipe de saúde.

\section{Vivendo o ideal: os benefícios do MC para a día de bebê-família}

$O$ contato pele a pele foi visto como algo que proporciona bem-estar, e ao ser realizado pela primeira vez revela sensações como alegria e emoção (SPEHAR MC e SEIDL EM, 2013). Maia JÁ, et al. (2011) corroboram com este achado, afirmando que o contato pele a pele realizado o mais brevemente possível, contribui para o melhor desenvolvimento do bebê e reduz os sentimentos negativos na família.

Os artigos analisados evidenciam que a proximidade com o recém-nascido pré-termo (RNPT), o calor físico e o contato pele a pele favorece a criação do vínculo entre família e o filho. Proporcionar aos pais a oportunidade de visualizar e tocar o filho logo após o nascimento, desde que possível, é extremamente útil para iniciar o vínculo afetivo, apego e, por consequência, favorecer o desenvolvimento da criança (COSTA R, et al., 2014).

Sobre a efetividade do aleitamento materno as publicações apresentam diferentes achados, a saber: $O$ artigo de (GUIMARAES GP e MONTICELLI M, 2007) demonstra que poder amamentar o bebê representa um avanço no processo de internação, sendo um acontecimento bastante sonhado pois concebe o cumprimento da função exclusiva materna de amamentar. Todavia, o estudo de (FURLAN CEFB, et al., 2003) afirma que a amamentação nesse contexto é cercada de avanços e retrocessos, onde mesmo com o encorajamento para a prática alguns RN têm dificuldade na pega ou voltam para alimentação via sonda. Como divergência identificou-se no artigo de (CAMPOS ACS, et al., 2008) que as puérperas desconheciam os benefícios do método para a amamentação revelando a falta de orientação e incentivo da prática.

Os pais também vivenciaram sentimentos positivos e boas sensações como tranquilidade satisfação, bemestar. Isto se deve a vivência no MC que faz com que elas percebam o avanço clínico como diferença na respiração, temperatura, ganho de peso e sono dos bebês. Além disso, a família se sente útil ao poder participar dos cuidados. A vivência no $M C$ promove na mãe a sensação de maior pertença da criança e um sentimento de vitória na família ao passarem por esta difícil etapa (LELIS BDB, et al., 2018).

O empoderamento das famílias foi observado em três estudos (SPEHAR MC e SEIDL EM, 2013; MOREIRA JO, et al.,2009; DUARTE ED e SENA RR,2004), os quais revelam a vivência dos pais como sujeitos do processo, com postura ativa, apropriando-se da prática do MC mesmo diante das incertezas. $\mathrm{O}$ MC desenvolve nas mães uma maior capacidade para realização de cuidados dos bebês do que os próprios 
profissionais de saúde, pois as puérperas demonstram maior sensibilidade às necessidades e ao desenvolvimento do RN (MEDINA JPL, et al., 2012).

Por fim, foi revelado como benefício do MC a troca de experiência entre os casais na UTIN ou na Unidade canguru. O processo de maternalidade, ou seja, a construção do cuidado materno, se torna mais fácil quando este é vinculado no grupo social das mães, ou seja, sentir-se e estar em família, participar do mundo de outras mães, reconhecer o filho como seu e aprender a comunicar-se com o bebê são passos a serem mais facilmente enfrentados em conjunto com outras mães (SÁ RC, et al., 2010).

\section{Vivendo o real: dilemas e dificuldades na efetivação do método canguru}

A prematuridade causa impactos emocionais nos pais, pois devido às condições físicas e clínicas do filho surgem os temores futuros, sobre sua sobrevivência e ainda sobre a capacidade de cuidar do bebê. Os pais até imaginam as necessidades do filho, porém é difícil trabalhar esses sentimentos, pois estão frustrados devido a ruptura da gestação, e ainda a necessidade de reorganizar os planos e dinâmica da família. Eles veem o recém-nascido como ser frágil e não correspondente ao sonhado e imaginado. Diante deste trauma, a criação de laços afetivos é conturbada, especialmente pelo sentimento de culpa (NUNES NP, et al., 2015; SPEHAR MC e SEIDL EM, 2013; CAETANO LC, et al., 2005; FURLAN CEFB, et al., 2003; GUIMARAES GP e MONTICELLI M, 2007; MOREIRA JO, et al., 2009; MARTINS AJVS e SANTOS IMM, 2008; DUARTE ED e SENA RR, 2004).

A permanência contínua no hospital faz com que a mãe ou pai rompa, mesmo que temporariamente com suas relações no contexto social. A rotina diária é modificada, as renúncias do trabalho, de estudos, do convívio com outros familiares ficam evidentes. Somado a isto, a saudade do lar e dos outros filhos geram ansiedade e preocupações. Isto torna a família vulnerável à ocorrência de distúrbios e desequilíbrios econômicos, sociais e culturais. Nos artigos analisados, este fator está mais associado à figura materna, fomentando a discussão da diferença de gênero e papéis na sociedade (NUNES NP, et al., 2015; OLIVEIRA MC, et al., 2015; FURLAN CEFB, et al., 2003; MOREIRA JO, et al., 2009; NEVES PN, et al., 2010; CAMPOS ACS, et al., 2008; MARTINS AJVS e SANTOS IMM, 2008; DUARTE ED e SENA RR, 2004).

Nesse sentido, Santos LM, et al. (2013) afirmam que com a falta de apoio social durante a permanência no MC, a mãe absorve a obrigatoriedade de estar integralmente ao lado do filho internado. Isto implica numa sobrecarga materna; pois, ela abdica dos seus papeis na sociedade para dedicar-se ao filho prematuro. Este fato diverge dos objetivos estabelecidos no MC, visto que é necessário incluir toda a família neste processo, com estímulo da presença do pai.

Com relação ao ambiente hospitalar, cinco artigos (DUARTE ED e SENA RR, 2004; GUIMARAES GP e MONTICELLI M, 2007; LARA KL e KIND L, 2014; NUNES NP, et al., 2015; CAMPOS ACS, et al., 2008) evidenciaram que este local causa angústias, pois na visão dos pais o mesmo se apresenta como hostil e assustador. Destacou-se a UTIN, justificado pela grande quantidade de profissionais diferentes, maquinários, temperatura fria, luzes, além de intervenções e procedimentos contínuos. A visão de um ambiente novo e assustador, somado às tarefas da equipe, o bebê real diferente do imaginário e ainda a culpa pelos problemas apresentados pelo filho, propiciam uma sensação de desamparo nos pais (GUIMARÃES GP e MONTICELLI $M, 2007)$.

Alguns artigos apontaram o desconforto sentido pelas mães devido á posição canguru e ao ambiente (ARIVABENE JC, TYRRELL MAR, 2010; OLIVEIRA MC, et al., 2015; FURLAN CEFB, et al., 2003; GUIMARAES GP e MONTICELLI M, 2007; NEVES PN, et al., 2010; MARTINS AJVS e SANTOS IMM, 2008). O compartilhamento de cuidados é essencial, porém não deve ser realizado de modo a causar sobrecarga nos pais, mas que eles compreendam a importância de desempenhar seu papel como mãe e pai junto ao filho (ANDRADE PR, et al., 2015).

O sentimento de medo e culpa foram evidenciados em sete dos artigos (NUNES NP, et al., 2015; SPEHAR MC e SEIDL EM, 2013; ARIVABENE JC, TYRRELL MAR, 2010; OLIVEIRA MC, et al., 2015; GUIMARAES GP e MONTICELLI M, 2007; MOURAI GN, et al., 2015; CAMPOS ACS, et al., 2008). O pavor surge em cada procedimento, no uso de novos dispositivos ou em uma nova doença adquirida durante a internação. O medo 
da perda do filho se faz presente nessas famílias continuamente, devido à fragilidade aparente do bebê. A culpa é proveniente da frustação de não poder ter um filho a termo como os outros casais. De acordo com os achados, estes sentimentos são refletidos em comportamentos divergentes: ou os pais se entregam totalmente e superprotegem os filhos ou agem com o distanciamento e desestímulo em praticar o MC.

Por fim, o episódio da alta hospitalar é algo discorrido de maneira ambígua nos artigos (GUIMARAES GP e MONTICELLI M, 2007; CAMPOS ACS, et al., 2008; DUARTE ED e SENA RR, 2004) visto que ao mesmo tempo em que a alta é algo sonhado e esperado pelos pais, a sensação de que o RN é mais bem cuidado no ambiente hospitalar causa dúvidas. Pois mesmo que o prematuro seja internado na UTIN, que receba todos os cuidados necessários para ganho de peso e estabilidade fisiológica e que os pais tenham tido a oportunidade de cuidar do seu filho, o momento da alta é temido por esses, pois existe o receio de que algo aconteça no lar (LUCCI MA, et al., 2013).

\section{Des(construção) da tríade no MC: família-bebê-equipe de saúde}

Dentre os profissionais de saúde que vivem a tríade e consequentemente são mais citados pelos pais no MC destacou-se os que compõem a equipe de enfermagem (NUNES NP, et al., 2015; SPEHAR MC e SEIDL EM, 2013; VIANA MRP, et al., 2018; CAETANO LC, et al., 2005; ARIVABENE JC, TYRRELL MAR, 2010; OLIVEIRA MC, et al., 2015; FURLAN CEFB, et al., 2003; GUIMARAES GP e MONTICELLI M, 2007; MOURAI GN, et al., 2015; NEVES PN, et al., 2010; CAMPOS ACS, et al., 2008; MARTINS AJVS e SANTOS IMM, 2008; DUARTE ED e SENA RR, 2004). A equipe de enfermagem ocupa lugar de destaque na efetivação do MC, pois mantem relações contínuas e direta com a família e o bebê em todas as etapas propostas (SILVA LJ, et al., 2009).

A orientação acerca do $M C$ é de extrema importância, pois as famílias vivenciam grandes dúvidas sobre como agir (NUNES NP, et al., 2015; VIANA MRP, et al., 2018; CAETANO LC, et al., 2005; ARIVABENE JC, TYRRELL MAR, 2010; OLIVEIRA MC, et al., 2015; FURLAN CEFB, et al., 2003; LARA KL e KIND L, 2014; MOURAI GN, et al., 2015; NEVES PN, et al., 2010).

Quando há o empenho da equipe em divulgar as ações do método, o interesse dos pais aumenta, pois, os mesmos percebem que podem ser úteis na recuperação do filho além de reiniciar o processo de maternagem e paternagem que foram fragmentados com o advento da prematuridade (NUNES NP, et al., 2015; CAETANO LC, et al., 2005; ARIVABENE JC, TYRRELL MAR, 2010; OLIVEIRA MC, et al., 2015; FURLAN CEFB, et al., 2003; NEVES PN, et al., 2010).

Ficou evidente que o apoio e acolhimento prestado aos pais, pela equipe, se configuram como incentivador do processo. Quando acolhidas, as mães sentem-se valorizadas e entendem que também estão sendo cuidadas, confirmando que o MC é uma estratégia que contempla a humanização e integralidade do cuidado, e que deve ser dirigida tanto ao bebê quanto à família (NUNES NP, et al., 2015; CAETANO LC, et al., 2005; OLIVEIRA MC, et al., 2015; GUIMARAES GP e MONTICELLI M, 2007; MOREIRA JO, et al.,2009; NEVES PN, et al., 2010; CAMPOS ACS, et al., 2008; MARTINS AJVS e SANTOS IMM, 2008; DUARTE ED e SENA RR, 2004). Coadunam as afirmações de Santos MH e Filho FM (2016) e Andrade PR, et al. (2015) de que a assistência prestada à família e o bebê necessita ser acolhedora, pois eles precisam perceber que os profissionais têm disponibilidade de dar atenção de forma individualizada.

A desconstrução da tríade também foi vivenciada pelos pais em três artigos (VIANA MRP, et al., 2018;LARA KL e KIND L, 2014;MOURAI GN, et al., 2015) quando evidenciaram que nem todos os pais conhecem o MC nem são informados de que maneira podem participar. Foi identificada uma postura coercitiva de alguns profissionais em dois artigos (GUIMARAES GP e MONTICELLI M, 2007; MOREIRA JO, et al.,2009). Ao assumir todos os cuidados neonatais, a equipe transparece um certo poder sobre estes bebês, consequentemente os pais acreditam que dentro daquele ambiente, apenas os profissionais é que devem cuidar do seu filho.

Adentrar no universo da prematuridade é se deparar com algo desconhecido. Nesse contexto, a mãe, especialmente, fica desorientada sem saber como agir e isso não se dá por escolha própria, vivendo a maternidade da forma que lhe é autorizada pelos outros (SÁ RC, et al., 2010). 
Assim, sempre que for viável, a equipe precisa oferecer subsídios para que os pais realizem os cuidados como de higiene e conforto, alimentação, dentre outros, buscando minimizar a sensação de incompetência e auxiliar na superação do medo em manusear o bebê que se apresenta frágil e pequenino. É importante usar de ferramentas como o elogio, parabenizando os progressos e valorizar os momentos em que estão juntos (GUIMARÃES GP e MONTICELLI M, 2007).

\section{CONSIDERAÇÕES FINAIS}

A vivência dos pais na primeira e segunda etapa do método canguru é permeada por múltiplos sentimentos, pelo reconhecimento dos benefícios do método, pelo enfrentamento de dificuldades e pela (des) construção de relações com equipe de saúde. Esse estudo traz contribuições ao conhecimento na área de saúde da criança, ao evidenciar a importância do $M C$ envolvendo seus protagonistas. A revisão integrativa evidenciou lacunas quanto à investigação dos aspectos sociais dos pais que vivenciam o MC no SUS.

\section{REFERÊNCIAS}

1. ANDRADE PR, et al. Facing the difficult experience even with support: The underage adolescent experiencing motherhood. Revista Gaúcha de Enfermagem, 2015; 36(esp):111-8.

2. ARIVABENE JC, TYRRELL MAR. Método mãe canguru: vivências maternas e contribuições para a enfermagem. Rev. Latino-Americana de Enfermagem, 2010; 18(2):262-268

3. BRASIL. Ministério da Saúde. Secretaria de Atenção à Saúde. Departamento de Ações Programáticas Estratégicas. Política Nacional de Atenção Integral à Saúde da Criança: orientações para implementação / Ministério da Saúde. Secretaria de Atenção à Saúde. Departamento de Ações Programáticas Estratégicas. - Brasília: Ministério da Saúde, 2018. $180 \mathrm{p}$.

4. BRASIL. Portaria SAS/MS no 1.683 de 12 de julho de 2007. Aprova, na forma de anexo, a Norma de Orientação para a Implantação do Método Canguru, destinado a promover a atenção humanizada ao recém-nascido de baixo peso e revoga a Portaria no 693/GM de 5 de julho de 2000, publicada no Diário Oficial da União no 129-E, de 6 de julho de 2000, Seção 1, página 15. Diário Oficial da União [da] República Federativa do Brasil, Poder Executivo, Brasília, DF, 13 jul. 2007. Seção 1, n. 134, p. 84.

5. BRASIL. Ministério da Saúde. Secretaria de Atenção à Saúde. Departamento de Ações Programáticas Estratégicas. Atenção humanizada ao recém-nascido de baixo peso: Método Canguru: manual técnico. 2. ed. Brasília: Ministério da Saúde, 2014.

6. CAETANO LC, et al. Vivendo no método canguru a tríade mãe-filho-família. Rev. Latino-Americana de Enfermagem, 2005; 13(4):562-568.

7. CAMPOS ACS, et al. Vivência no método mãe canguru: percepção da mãe. Revista Rene, 2008; 9(3):28-36.

8. COSTA R, et al. Da incubadora para o colinho: o discurso materno sobre a vivência do método canguru. Revista de Enfermagem e Atenção Saúde, 2014; 3(2):41-53.

9. DUARTE ED, SENA RR. Experiências de mulheres no desenvolvimento do Método Canguru. Revista Mineira de enfermagem, 2004; 8(4):436-441.

10. FRANCA EB, et al. Principais causas da mortalidade na infância no Brasil, em 1990 e 2015: estimativas do estudo de Carga Global de Doença. Revista Brasileira de Epidemiologia, 2017; 20(1): 46-60.

11. FURLAN CEFB, et al. Percepção dos pais sobre a vivência no método mãe-canguru. Revista Latino-Americana de Enfermagem, 2003; 11(4):444-452.

12. GONTIJO TL, et al. Avaliação da implantação do Método Canguru por gestores, profissionais e mães de recémnascidos. Caderno de Saúde Pública, 2012; 28(5):935-944.

13. GUIMARÃES GP, MONTICELLI M. A formação do apego pais/recém-nascido pré-termo e/ou de baixo peso no método mãe-canguru: uma contribuição da enfermagem. Texto \& Contexto Enfermagem, 2007; 16(4): 626-635.

14. JESUS NC, et al. A vivência do método canguru: a percepção do pai. Revista de enfermagem UFPE, 2015; 9(7):854250.

15. LARA KL, KIND L. Processos de subjetivação vivenciados por mães em uma unidade de neonatologia. Psicologia em estudo, 2014; vol.19, n.4, pp.575-585.

16. LELIS BDB, et al. Acolhimento materno no contexto da prematuridade. Revista de enfermagem UFPE, 2018; 12(6):1563-9.

17. LUCCI MA, et al. Profissionais de enfermagem e suas representações sociais sobre o método mãe canguru. Acta Academica, 2013; p. 150-3. 
18. MAIA JÁ, et al. Método Canguru: a importância da família na recuperação do recém-nascido de baixo peso. Revista Enfermagem em foco, 2011; 2(4):231-234.

19. MARTINS AJVS, SANTOS IMM. Vivendo do outro lado do método canguru: a experiência materna. Revista Eletronica de Enfermagem, 2008; 10(3):703-10.

20. MEDINA JPL, et al. Programa madre canguro: una alternativa sencilla y costo eficaz para la protección de los recién nacidos prematuros o con bajo peso al nacer. Revista de salud pública, 2012; 14(2): 32-45.

21. MENDES KDS, et al. Revisão integrativa: método de pesquisa para a incorporação de evidências na saúde e na enfermagem. Texto contexto - enfermagem, 2008; 17(4):758-764.

22. MENEZES MAS, et al. Recém-nascidos prematuros assistidos pelo Método Canguru: avaliação de uma coorte do nascimento aos seis meses. Revista Paulista de Pediatria, 2014; 32(2): 171-177.

23. MOREIRA JO, et al. Programa mãe-canguru e a relação mãe-bebê: pesquisa qualitativa na rede pública de Betim. Psicologia em Estudo, 2009; v. 14, n. 3, p. 475-483.

24. MOURAI GN, et al. A vivência do método canguru - a percepção do pai: estudo descritivo-exploratório. Revista de enfermagem UFPE, 2015.

25. NASCIMENTO ACST, et al. Redes Sociais de Apoio as famílias de prematuros que vivenciam a hospitalização: Um estudo Transcultural. Revista Eletrônica Acervo Saúde, 2019; (37), e1986

26. NEVES PN, et al. Atenção humanizada ao recém-nascido de baixo-peso (método Mãe Canguru): percepções de puérperas. Revista Gaúcha de Enfermagem, 2010; vol.31, n.1, pp.48-54.

27. NUNES NP, et al. Método canguru: percepção materna acerca da vivência na unidade de terapia intensiva neonatal. Revista brasileira de promoção a saúde, 2015; 28(3): 387-393

28. OLIVEIRA MC, et al. Método canguru: percepções das mães que vivenciam a segunda etapa. Revista de Pesquisa Cuidado é Fundamental Online, 2015; vol. 7, núm. 3 pp. 2939-2948.

29. Pesquisa nacional por amostra de domicílios: síntese de indicadores 2015 / IBGE, Coordenação de Trabalho e Rendimento. - Rio de Janeiro: IBGE, 2016. 108p. Disponível em: < https://biblioteca.ibge.gov.br/visualizacao/livros/liv98887.pdf > Acesso em 01 de julho de 2018

30. SÁ RC, et al. Relações interpessoais entre os profissionais e as mães de prematuros da unidade canguru. Revista Brasileira de Promoção à Saúde, 2010; 23(2):144.

31. SANTOS LM, et al. Percepção materna sobre o contato pele a pele com o prematuro através da posição canguru. Revista de Pesquisa: Cuidado é Fundamental Online, 2013; 5(1):3504-14.

32. SANTOS MH, FILHO FM. Benefícios do método mãe canguru em recém-nascidos pré-termo ou baixo peso: uma revisão da literatura. Universitas: Ciências da Saúde, 2016; 14(1): 67-76.

33. SILVA LJ, et al. Tecnologia e humanização na UTIN: reflexões no contexto do processo saúde doença. Revista Escola de Enfermagem ,2009; 43(3):684-9.

34. SPEHAR MC, SEIDL EM. Percepções maternas no Método Canguru: contato pele a pele, amamentação e autoeficácia. Psicologia em estudo, 2013; 18(4): 647-656.

35. STETLER CB, et al. Newell-Stokes V. Evidence-based practice and the role of nursing leadership. J Nurs Adm ,1998; 28(7-8):45-53.

36. TRICCO AC, et al. PRISMA Extension for Scoping Reviews (PRISMA-ScR): Checklist and Explanation. Ann Intern Med, 2018; 169(7):467-473.

37. VERONEZ M, et al. Vivência de mães de bebês prematuros do nascimento a alta: notas de diários de campo. Revista Gaúcha de Enfermagem, 2017; 38(2):e60911.

38. VIANA MRP, et al. Vivência de Mães de Prematuros no Método Mãe Canguru. Fundamental Care Online, 2018; 10(3):690-695. 